\title{
Patrimônios Afetivos: Um Roteiro Turístico a Partir Da Memória De Idosos
}

\author{
Patrimonios Afectivos: Un Itinerario Turístico desde la Memoria De \\ Ancianos
}

\author{
Affective Assets: A Tourist Route from the Memory of the Elderly
}

\author{
Milena Behling Oliveira ${ }^{1}$ \\ Diego Lemos Ribeiro ${ }^{2}$
}

\begin{abstract}
Resumo
O estudo em questão é um recorte de uma pesquisa de mestrado intitulado Lugares de Memória: Patrimônios afetivos de Morro Redondo-RS, que se encontra em desenvolvimento no programa de pós-graduação em Memória Social e Patrimônio Cultural da Universidade Federal de Pelotas. Partiremos da premissa que os patrimônios de uma cidade não se configuram apenas a partir de bens tombados ou registrados juridicamente, entendemos nessa pesquisa, os patrimônios como referenciais que estão ligados aos moradores locais por meio dos afetos. O objetivo da pesquisa em questão é a identificação dos Patrimônios Afetivos da cidade de Morro Redondo-RS na visão dos idosos. As narrativas dos indivíduos indicam lugares de memória que os mesmos consideram patrimônios, porém, não visto pelo âmbito do patrimônio consagrado que conhecemos, mas pela afetividade que esses lugares despertam nos sujeitos. No escopo da pesquisa, designamos esses referenciais como Patrimônios Afetivos. Em termos metodológicos, essa pesquisa se configura como qualitativa e enquadrada na pesquisa social, foi utilizado metodologicamente entrevistas e relatos para obtermos os resultados da pesquisa. Isto posto, para o recorte pretendido neste estudo, buscamos debater como os patrimônios afetivos identificados podem ajudar na formação de um novo roteiro turístico para a região de Morro Redondo. E por fim, apresentar desdobramentos empíricos de patrimônios afetivos já identificados.
\end{abstract}

Palavras-Chave: Afeto; Idoso; Lugares de Memória; Patrimônio; Roteiro turístico.

\section{Resumen}

El estudio en cuestión es un recorte de una investigación de maestría titulada Lugares de Memoria: Patrimonios afectivos de Morro Redondo-RS, que se encuentra en desarrollo en el programa de postgrado en Memoria Social y Patrimonio Cultural de la Universidad Federal de Pelotas. Partimos de la premisa que los patrimonios de una ciudad no se configuran sólo a partir de bienes tomados o registrados jurídicamente, entendemos en esa investigación, los patrimonios como referenciales que están ligados a los habitantes locales por medio de los afectos. El objetivo de la investigación en cuestión es la identificación de los Patrimonios Afectivos de la ciudad de Morro Redondo-RS en la visión de los ancianos. Las narrativas de los individuos indican lugares de memoria que los mismos consideran patrimonios, pero no visto por el ámbito del patrimonio consagrado que conocemos, sino por la afectividad que esos lugares despiertan en los sujetos. En el ámbito de la investigación, designamos estos referenciales como Patrimonios Afectivos. En términos metodológicos, esta investigación se configura como cualitativa y encuadrada en la investigación social, se utilizó metodológicamente entrevistas y relatos para obtener los resultados de la investigación. Esto puesto, para el recorte pretendido en este estudio, buscamos

\footnotetext{
${ }^{1}$ Mestranda em Memória Social e Patrimônio Cultural; Universidade Federal de Pelotas; Pelotas, RS, Brasil; milena.brs@gmail.com.

${ }^{2}$ Doutor em Arqueologia; Instituto de Ciências Humanas- UFPEL. Pelotas, RS, Brasil. dlrmuseologo@yahoo.com.br.
} 
debatir cómo los patrimonios afectivos identificados pueden ayudar en la formación de un nuevo itinerario turístico para la región de Morro Redondo. Y por último, presentar desdoblamientos empíricos de patrimonios afectivos ya identificados.

Palabras claves: Afecto; Ancianos; Lugares de memoria; Patrimonio; Ruta turística.

\begin{abstract}
The study in question is a cut of a master's research entitled Places of Memory: Morro Redondo-RS affective patrimony, which is under development in the postgraduate program in Social Memory and Cultural Heritage of the Federal University of Pelotas. We will start from the premise that the patrimonies of a city are not only configured from legally registered assets, we understand in this research, the heritage as references that are linked to the local residents through the affections. The objective of the research in question is the identification of the Affective Assets of the city of Morro Redondo-RS in the view of the elderly. The narratives of the individuals indicate places of memory that they consider patrimony, but not seen by the scope of the consecrated heritage that we know, but by the affectivity that these places awaken in the subjects. In the scope of the research, we designate these references as Affective Assets. In methodological terms, this research is configured as qualitative and framed in social research, methodologically used interviews and reports to obtain the results of the research. This, for the purpose of this study, seeks to discuss how the identified affective heritages can help in the formation of a new tourist route for the region of Morro Redondo. And finally, to present empirical developments of affective heritage already identified.
\end{abstract}

Keywords: Affection; Old man; Memory Places; Patrimony; Sightseeing tour.

\title{
1. Introdução
}

Em nosso entendimento, os referenciais identificados nesse estudo estabelecem conexões afetivas com os sujeitos, pois esses lugares se tornam companheiros emocionais e ancoradouros de memórias. "As cidades que habitamos, os prédios que ocupamos, os espaços pelos quais transitamos, os objetos que utilizamos e as imagens que contemplamos cumprem o papel de mediadores das nossas experiências nesse nosso ambiente" (DOHMANN, p 36, 2013). São esses patrimônios afetivos os mediadores das experiências dos idosos de Morro Redondo.

Visto que, se questionarmos os moradores de Morro Redondo-RS sobre o que os mesmos consideram patrimônios, provavelmente teremos como respostas patrimônios ligados às vivências e emoções. E é exatamente por esta esfera que intencionamos desenvolver um novo pensamento a respeito do patrimônio. O município de Morro Redondo se encontra em grande parte em meio rural, sendo sua localização aproximadamente $296 \mathrm{~km}$ da cidade de Porto Alegre, capital do estado do Rio Grande do Sul, Brasil. A cidade do interior do estado foi primeiramente colonizada por portugueses, porém, em 1875, houve a chegada de italianos e, no ano de 1886, alemães e pomeranos (PREFEITURA MUNICIPAL DE MORRO REDONDO, 2018). 


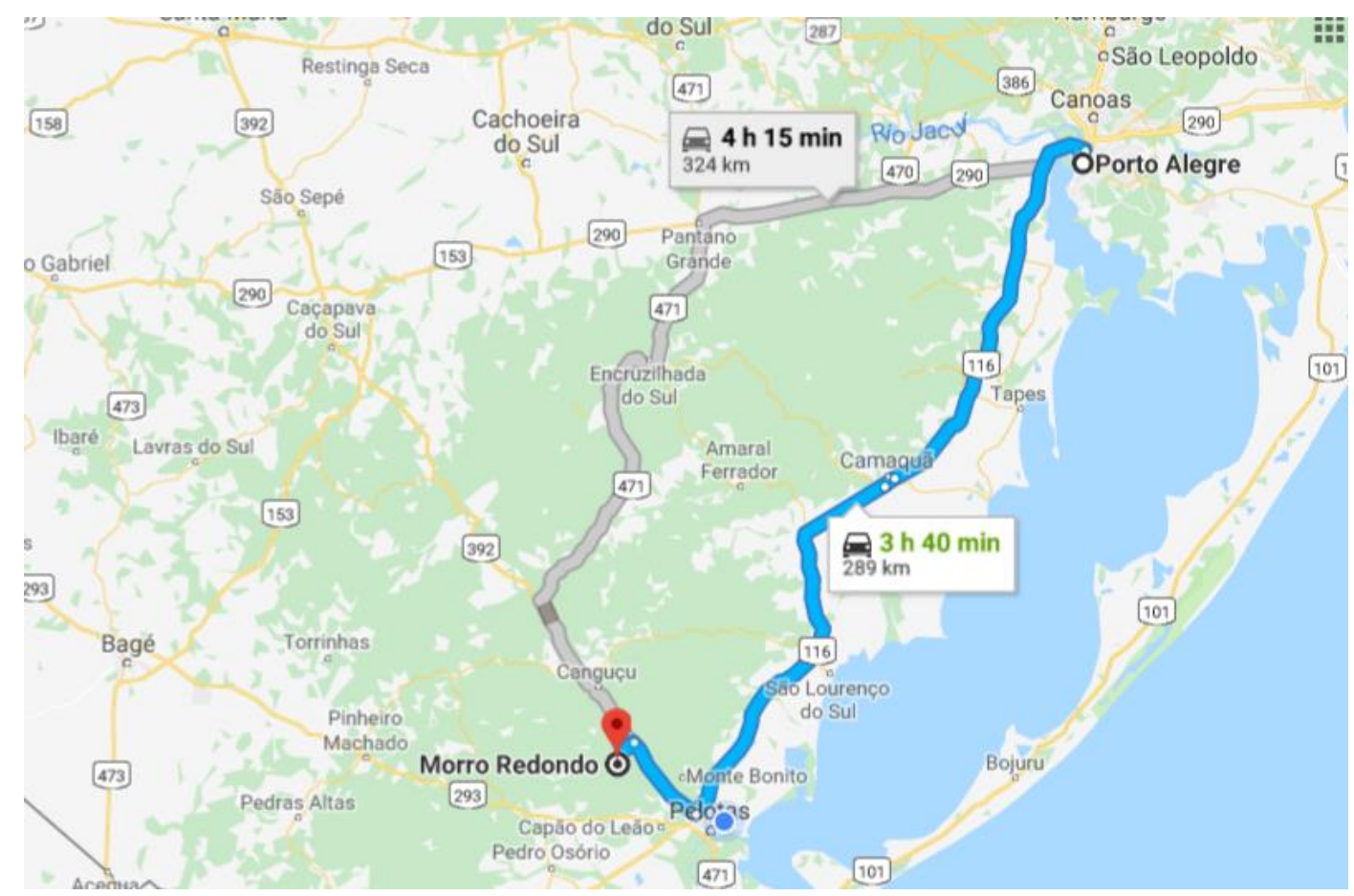

Figura 1: Mapa distancia de Porto Alegre à Morro Redondo.

Fonte: Google maps, 2019.

Morro Redondo inicialmente fazia parte de um distrito da cidade de Pelotas, município vizinho, tendo sua emancipação em abril de 1988. A cidade apresenta certa de 6.546 pessoas segundo o IBGE (2018). O município possui um museu chamado "Museu Histórico de Morro Redondo", criado no ano de 2009, pelos moradores do município, com o intuito de preservar e relembrar as memórias locais. Nele, é desenvolvido um projeto ${ }^{3}$ de extensão por meio da Universidade Federal de Pelotas, que se localiza na cidade vizinha.

Com diversas ações visando, em síntese, à interação do Museu com a comunidade local. Todas as exposições e ações educativas realizadas no Museu têm a participação da população, principalmente dos idosos, pois são protagonistas de diversas ações, como o Café com Memórias. Esse diálogo com os moradores é de fundamental importância, pois acreditase em um Museu em constante construção e que interaja com as distintas parcelas da comunidade. Sendo assim, o Museu possui parceria com diversos atores, sendo alguns deles, Universidade Federal de Pelotas, Associação Amigos da Cultura, Prefeitura Municipal de Morro Redondo, Escolas da cidade, Associação do Roteiro Turístico Morro de Amores.

\footnotetext{
${ }^{3}$ Museu Morro-Redondense: Espaço de Memórias e Identidades, coordenador: Diego Ribeiro. Trata-se de um projeto de extensão vinculado à Pró-Reitoria de Extensão e Cultura da Universidade Federal de Pelotas. Este projeto conta com a colaboração de estudantes voluntários, inclusive a autora deste trabalho.
} 
A atividade Café com Memórias citada acima utiliza objetos do acervo do Museu para a evocação de memórias individuais em confluência com as memórias coletivas do grupo; já que se manifestam por meio de relatos orais, músicas, brincadeiras e outros. Por meio dessa atividade, além de narrarem sobre os objetos museológicos, observou-se que os idosos relataram a respeito de lugares da cidade com notável carga afetiva, porém, ao rememorar os idosos descrevem os lugares como eram a anos atrás e não como nos dias atuais. Desta forma, foi proposto para os mesmos uma ação denominada Caminhada da Percepção, na qual estes idosos acompanhados por um grupo de estudantes de uma escola do município, visitaram os locais mencionados. É, portanto, partindo dessas atividades que esta pesquisa se desenvolveu.

Porém, quais são e como se manifestam esses patrimônios afetivos narrados pelos idosos? Quais seriam os limites e extensões dos patrimônios afetivos em relação às memórias sociais? É o que pretendemos desenvolver ao longo deste estudo. Em vista disso, foi utilizado metodologicamente as narrativas, relatos e depoimentos dos idosos, já que sabemos que para manter o espírito dos lugares (QUEBÉC, 2008) é de suma importância sua transmissão. O estudo em questão é de cunho qualitativo e se enquadra na pesquisa social, e teve como parâmetros para estabelecer os patrimônios afetivos a recorrência dos mesmos nas narrativas. Já os locais identificados por apenas um indivíduo, foram considerados como uma memória afetiva. Porém, para viabilizar o estudo foi necessário a delimitação de um espaço, portanto foram identificados os patrimônios afetivos da avenida Jacarandá, principal rua da cidade.

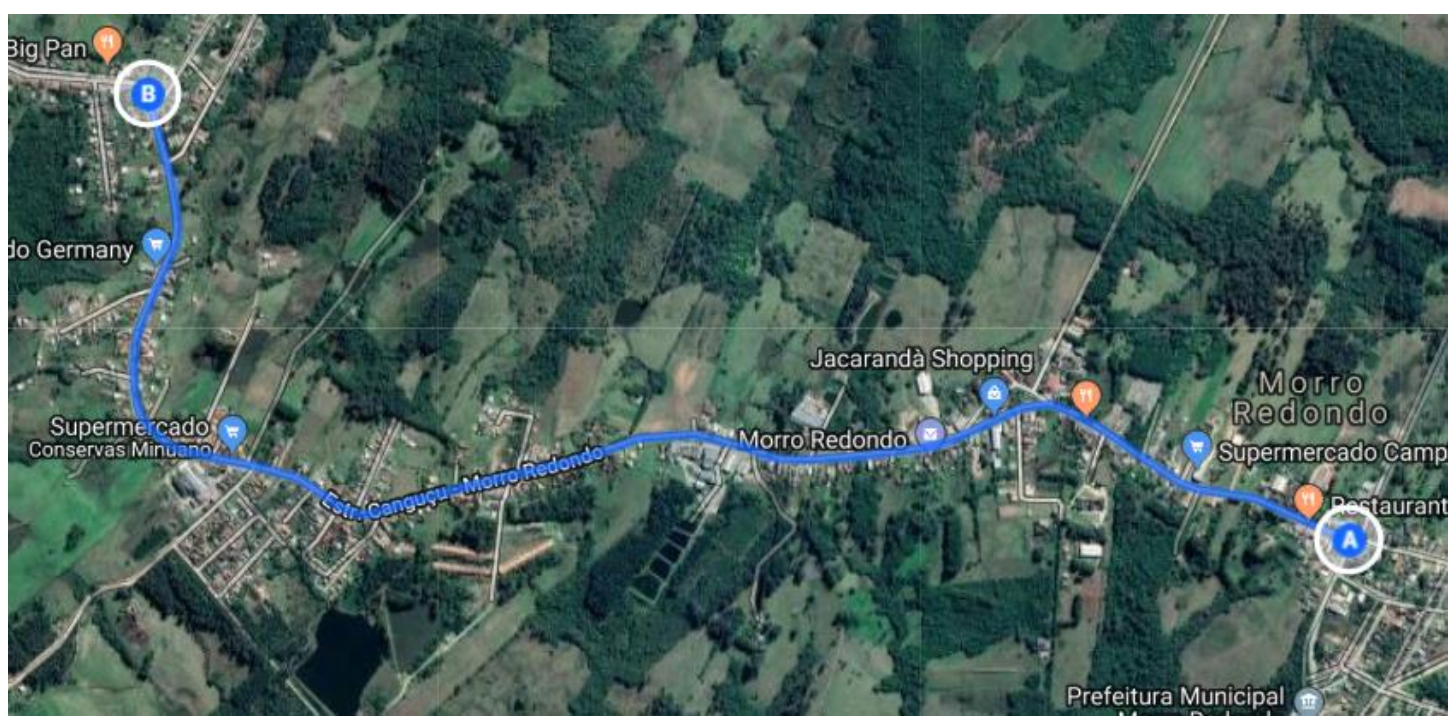

Figura 2: Avenida Jacarandá-Morro Redondo RS. Fonte: Google maps, 2019.

O patrimônio de que estamos falando vai de encontro ao patrimônio formal, que é objetivo. Já o patrimônio afetivo está ligado aos efeitos gerados nos sujeitos, não tendo seu 
valor baseado nas tangibilidades. Desta forma, não estamos trabalhando com referências monumentais ou das belas artes, como geralmente é o nosso patrimônio oficial, mas estamos expressando sobre o que em um primeiro momento pode ser visto como banal. Entretanto, estão guarnecidos de significados e afetos, esses que convertessem em fatores positivos para o reconhecimento e preservação de um patrimônio. Pois, possibilita uma relação mais íntima entre os sujeitos e os bens, o que consequentemente reflete em apropriação e identificação.

\section{Patrimônios Afetivos: Um Recurso para um Desenvolvimento Turístico Sustentável}

A cidade Morro Redondo-RS não possui monumentos históricos, obras de artes, porém, recentemente teve um bem imaterial registrado como patrimônio. São eles os doces coloniais apontados pelo IPHAN no livro dos saberes ${ }^{4}$, esse reconhecimento ocorreu enquanto esta pesquisa encontrava-se em desenvolvimento, mais precisamente em 15 de maio de 2018. A alguns anos vinha sendo realizado estudos através de pesquisas realizadas pelo curso de Antropologia da Universidade Federal de Pelotas (UFPel) o que possibilitou que a tradição doceira fosse declarada patrimônio imaterial. O tombamento abrangeu além de Morro Redondo as cidades de Pelotas, Arroio do Padre, Capão do Leão e Turuçu.

Já quando falamos de patrimônios informais do município, nos deparamos com objetos, lugares, manifestações do cotidiano, ligados a cultura e a vida em uma cidade do interior, desta maneira nos referimos a um patrimônio local e não chancelado. Ao pensar em um patrimônio informal, de um ponto de vista afetivo, percebemos que o município é rico em patrimônios. Há uma vontade de memória (NORA 1993) por parte da população MorroRedondense, principalmente pelos idosos da cidade que anseiam pela preservação dos lugares de memória da cidade. "O patrimônio é menos um conteúdo que uma prática de memória, obedecendo a um projeto de afirmação de si mesma" (NORA, 1993 p. 163).

Diante desses acontecimentos de cunhos patrimoniais e também por a cidade se encontra com dificuldades financeiras, devido ao fechamento de uma grande indústria do município, os moradores locais buscaram novas formas de desenvolvimento econômico. Sendo assim, Morro Redondo vem se desenvolvendo turisticamente recentemente, sendo que, atualmente possui um roteiro turístico denominado "Morro de amores". Onde é oferecido aos turistas o seguimento turismo rural. O roteiro também realiza festas temáticas a cada três

\footnotetext{
${ }^{4}$ Foi verificado a existência de patrimônios tombados nos sites do IPHAN: http://portal.iphan.gov.br a nível estadual IPHAE: http://www.iphae.rs.gov.br/Main.php?do=BensTombadosAc\&Clr=1 e a nível local Prefeitura de Morro Redondo: http://www.pmmorroredondo.com.br/index.html
} 
meses na busca de divulgar os atrativos da região. Esse roteiro foi criado por um grupo de empreendedores do município e conta com a parceria do Sebrae, pois, a cidade não dispõe no setor público de uma estrutura para o desenvolvimento turístico. Como por exemplo turismólogos, secretária de turismo, profissionais da área que possam ir em busca de recursos. Desta maneira, foi criado uma associação dos empreendedores do roteiro e um conselho municipal de turismo, que visa debater e organizar ações para o desenvolvimento local.

Tratando do estudo de que se fala, para a identificação dos patrimônios afetivos de Morro Redondo, partimos das atividades desenvolvidas em conjunto com o Museu de Morro Redondo, salientando a relevância dos museus nos processos de patrimonialização e de relação com a comunidade, por meio dos projetos exteriorizados. De Varine (2012) evidencia que os Museus são considerados em todos os países as instituições mais representativas do patrimônio e das ações sobre o mesmo. Portanto, o Museu é um instrumento de ativação patrimonial e de desenvolvimento local.

Em busca de um desenvolvimento local e de um avivamento da cultura o Museu de Morro Redondo é um colaborador do roteiro Morro de Amores, sendo assim, o Museu se faz presente nos eventos realizados pelo roteiro. Desta forma, em um desses eventos foi proposto a realização da atividade Caminha da Percepção. Desta forma, os idosos serviram de guias para a visitação dos Patrimônios Afetivos, tendo como intenção instigar os moradores locais e turistas que visitavam a cidade no momento. No entanto, precisamos ter em mente que essas ações também agem de forma terapêutica para os idosos, pois os mesmos se sentem uteis contando as histórias e vivencias desses lugares.

Semanas antes do evento por meio das redes sociais do Museu de Morro Redondo, já realizávamos um trabalho de divulgação, para que as pessoas participassem e compartilhassem suas memórias. Portanto, no dia do evento foram colocadas placas nos lugares onde os Patrimônios Afetivos se localizam. Nestas placas constava uma parte das memórias coletadas previamente pelas narrativas dos idosos e um símbolo de QR CODE, para que todos pudessem acessar e contribuir com as suas memórias, de forma retroalimentada.

Com a realização desta ação em conjunto, podemos perceber o quanto foi eficaz a junção de um possível novo roteiro turístico com as atividades já existentes. E ainda com a participação da comunidade local, algo fundamental já destacado por Prats (2005) e De Varine (2012). Seguindo o viés de pensamento que a comunidade deve participar do processo de declaração de um patrimônio. Prats (2005) destaca a importância da participação da comunidade e De Varine (2012), em sua obra As raízes do futuro: o patrimônio a serviço do desenvolvimento local, propõe debater o desenvolvimento local. Porém, não como um 
conteúdo acadêmico visto apenas pelos livros e aulas, mas sim partindo de uma vivência prática, com um contato com a comunidade local, visando vislumbrar a realidade do local. $\mathrm{O}$ patrimônio, em suas diferentes formas, é uma estrutura para o desenvolvimento local, todavia, só desenvolve seu papel se for utilizado de forma efetiva, ativa e consciente da parte da comunidade que o detém, isto é, um patrimônio que encontre uma harmonia e contribua com o progresso de sua comunidade.

Neste sentido, Prats (2005) propõe que o patrimônio local não seja considerado como de princípios abstratos de legitimação, mas como um fórum de memória, em toda a sua complexidade, refletividade poliédrica em apoios diversos, que com base nas preocupações e desafios do presente, refletem sobre o passado, projetando participativamente o futuro. Esta é a maneira do autor entender o patrimônio como "Recursos para viver" (PRATS, 2005 p.16). Em Morro Redondo para os idosos, esses patrimônios afetivos servem exatamente para o que Prats (2005) salienta, um recuso para viver, pois como já abordado anteriormente, para aqueles sujeitos pouco importa o patrimônio consagrado. Visto que, os patrimônios afetivos são artifícios para a manutenção de suas próprias vidas.

E é considerando esta realidade do município de Morro Redondo que este trabalho vem sendo desenvolvido. Pois, sabemos das dificuldades que as cidades do interior enfrentam, como pouca mão de obra, falta de infraestrutura e a crise financeira que se alastra por todo país. Portanto, pensamos em um patrimônio principiado de uma consciência coletiva, que seja usufruído para viver, produzir e que continue em transformação para prosseguir em uso e sendo útil, obtém reconhecimento e trazendo benefícios para a comunidade. Além disso, esses patrimônios devem servir ou vir a servir para algo, tornando-os vivos e necessários para manter a identidade das comunidades. "A esterilização sob o pretexto de conservar um valor raro leva inevitavelmente à perda de uma grande parte de seu significado" (DE VARINE, 2012, 64).

Esse cenário que encontramos na cidade de Morro Redondo, também nos faz pensar em um turismo de base local, que é definido por Coriolano (2003) como uma iniciativa por parte dos moradores locais, sendo os mesmos, os principais articuladores do desenvolvimento turístico. Trabalhando para que os lucros gerados pelo turismo permaneçam na comunidade. Deste modo, colaborando para uma melhor qualidade de vida da população local. Porém, se faz necessário uma apropriação dos moradores locais, fazendo com que os mesmos se sintam parte das ações, um agente indispensável e valorizado por ser o detentor do local.

Portanto, os Patrimônios Afetivos, servem de estímulos para os moradores da cidade. Pois, foram pessoas da comunidade que realizaram a identificação, que escolheram alguns 
locais que contam as suas histórias, representam vivencias e a cultura que os mesmos querem repassar para as próximas gerações. Desta forma, gerando um pertencimento, divulgando algo que eles realmente acreditam ser algo de valor, seja este valor, simbólico, emocional, afetivo.

De acordo com Luchiari (1998) o turismo possibilita a criação e traz para os dias atuais antigas práticas, costumes, folclore que estavam adormecidas com o tempo. Trazendo a oportunidade de novos atrativos turísticos, baseado na cultura local, o que deve ser tratado com cuidado, pois estamos lidando com "coisas" que pertencem a uma comunidade especifica. Portanto, devemos consulta-los e incluir os moradores nas decisões. Mas, que por outro lado, pode ser utilizada de forma positiva, ajudando na preservação, divulgação da cultura e trazendo desenvolvimento econômico.

\footnotetext{
Além de uma mescla de pessoas e culturas diferentes, o turismo - tanto o internacional quanto o interno - gera uma considerável redistribuição espacial da capacidade de auferir renda, com um impacto significativo sobre a economia da área de destino (COOPER, 2001, p. 85).
}

Quando utilizamos dos lucros obtidos com o turismo para o desenvolvimento local, geramos renda, propiciamos ações para fomentar a cultura, assim como também promover, difundir e preservar o patrimônio. No caso em questão, todas essas ações fortalecem os Patrimônios Afetivos. Pois, esses patrimônios fazem parte da cultura local e já existem, o que diminui o custo de investimento. Ou seja, um atrativo que depende diretamente dos moradores locais. Pois, eles são os atores sociais indispensáveis para narrar sua cultura.

\section{Desdobramento Empírico de um Patrimônios Afetivo}

Entre os patrimônios afetivos identificados encontrasse o local intitulado Cine Recreio Familiar, que se localiza na Avenida Jacarandá, era conhecido por realizar inúmeros bailes e por ser sede central do clube Esportivo Índio, onde o mesmo também realizava seus eventos no local. Mas, além disso, o lugar também abrigava o cinema da cidade. De acordo com relatos orais foi construído por Emilio Lang e o primeiro proprietário foi Adolfo Kutter.

Atualmente encontra-se em funcionamento neste local uma padaria, mas ainda permanece preservada a fachada original do prédio, nos possibilitando visualizar o nome Recreio Familiar. Esse lugar é descrito como mais acessível pelos entrevistados, pois diferente dos outros locais da cidade onde ocorriam bailes, o Cine Recreio Familiar não era uma sociedade.

No entanto, também era um lugar de convívio familiar e com normas para poder participar dos eventos, sendo uma delas a forma de se vestir: homens de terno e mulheres com roupas longas. Esse lugar de memória possui uma relação intensa com os indivíduos, há um 
envolvimento e compartilhamento, como se todos fizessem parte de uma grande família. Desta forma, dizemos que há uma coletividade, descrita nas entrevistas.

Eu me divertia aqui na comunidade advento, e lá no recreio familiar. E como era lá no recreio familiar? Aquilo era muito, ali não era sociedade, era toda gente, tudo era conhecido. A dona que tinha ali ela liberava para nós abrir uma porta para casa dela na sala, e ai nos botava as crianças tudo a dormir na sala ali e ia dançar volta e meia ia lá espiar, ela botava colchão no chão e tudo (LILI, 2018).

Também havia no Cine Recreio Familiar bailes específicos, onde era possível que as mulheres da época tirassem os homens para dançar. Esse momento era chamado de traval, onde uma boneca era pendurada no salão. Mas os entrevistados destacam que esse tipo de baile era esporádico.

$\mathrm{Eu}$ tenho curiosidade para saber como era esses bailes, porque dizem que era diferente né esses bailes do cine recreio familiar, como era? Ahh é os homens convidavam a gente para dançar e depois era traval e ai pendurava uma boneca ai as mulheres tinham que convidar pra dançar. E a senhora convidava? ahh Convidava (risos) (ERICA, 2018).

Analisando esta narrativa da senhora Erica, entendemos que também há uma seleção de memórias, os momentos vivenciados podem ser guardados na memória por suas diferenças, como é o caso do traval, um acontecimento circunstancial e que diferencia esses bailes dos outros. De acordo com Halbwachs (1990),

a memória não tem alcance sobre os estados passados e não nô-los restitui em sua realidade de outrora, senão em razão de que ela não os confunde entre si, nem com outros mais antigos ou mais recentes, isto é, ela toma seu ponto de apoio nas diferenças (p.96).

Contudo, o tempo também interfere na diferenciação das lembranças, do qual, as divisões temporais são especificas para cada comunidade e para cada sujeito. O tempo demonstra continuamente as mudanças, já o espaço oferece uma imagem de permanência e estabilidade. Desta forma, os sujeitos incorporam traços dos lugares e os lugares possuem vestígios de um grupo. O lugar ocupado pelo grupo é um aglomerado de elementos e memórias da vida social. Ele faz lembrar cada particularidade, costumes de outros tempos, pessoas e relações sociais, o lugar é fonte e testemunha do passado (HALBWSCHS, 1990).

Além de uma relação direta entre os sujeitos entrevistados e os lugares, percebemos que cada lugar possui particularidades, rituais específicos, que dinamizam as atividades. Os lugares de memória apresentados carregam consigo uma transposição de afetos. Sendo eles, afetos por pessoas que não se encontram mais presentes, mas que de alguma forma se encontram no local, afeto por acontecimentos que não são possíveis reviver, mas que o 
Recreio Familiar ajuda a relembrar. Ele é o gatilho que possibilita o despertar das memórias afetivas.

E se eu perguntar para a senhora assim, de um lugar que a senhora sinta saudade, que se pudesse voltar no tempo a senhora traria de volta, o que seria? É tinha muitas amigas né e amigos a gente saia também para outros bailes outros lugares, mas o baile do cinema eu gostava. Era onde mais a gente ia né era o mais perto, os pais não deixavam ir muito longe. E desde criança a gente foi criado nessa comunidade, e tinha juventude, reunião de juventude (ERICA, 2018).

Esse lugar do qual estamos tratando demostra uma relação metonímica com a externalidade cultural dos Morro-Redondenses. Desta forma, ao constatarmos esta conexão, podemos disser que o Recreio Familiar faz parte de um patrimônio local (PRATS, 2005). Ele é de interesse da comunidade, não é um patrimônio institucionalizado, mas possui representatividade perante os moradores locais.

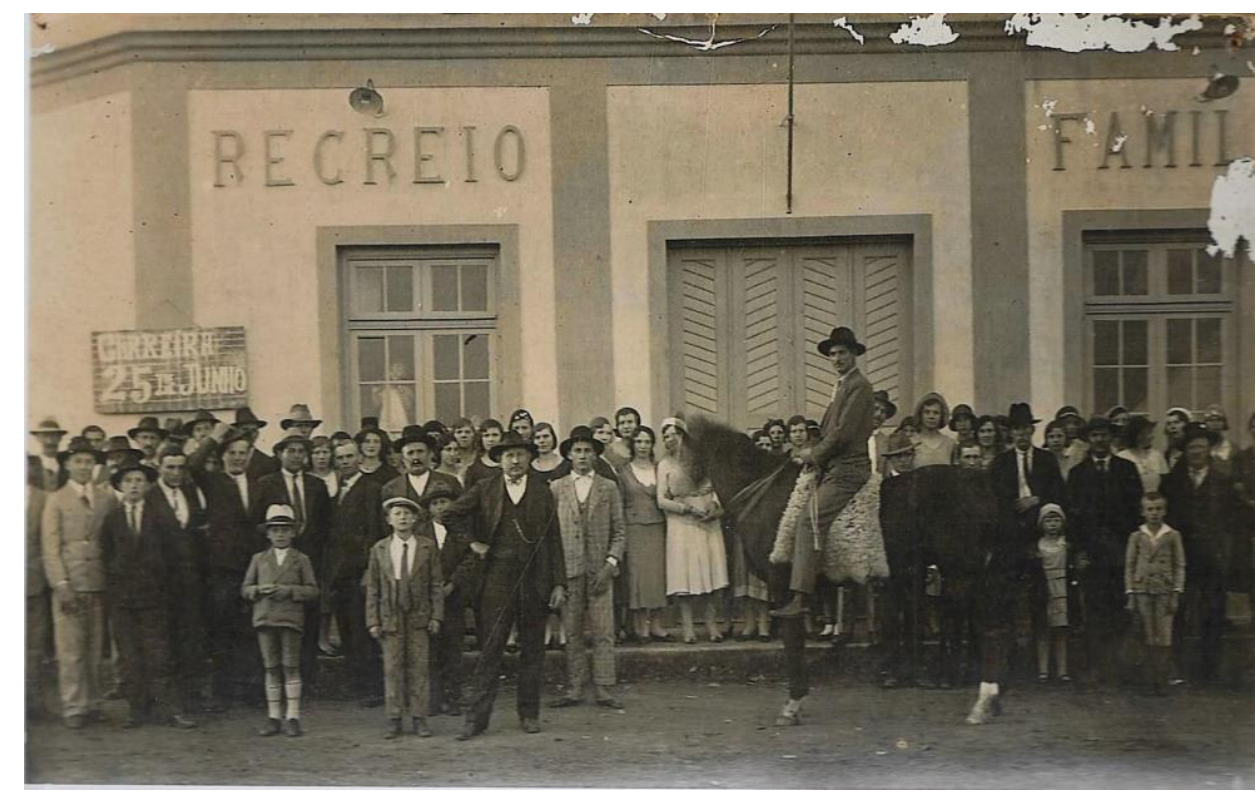

Fotografia 3: Recreio Familiar Fonte: Arquivo pessoal de dona Veronica, 2018. 


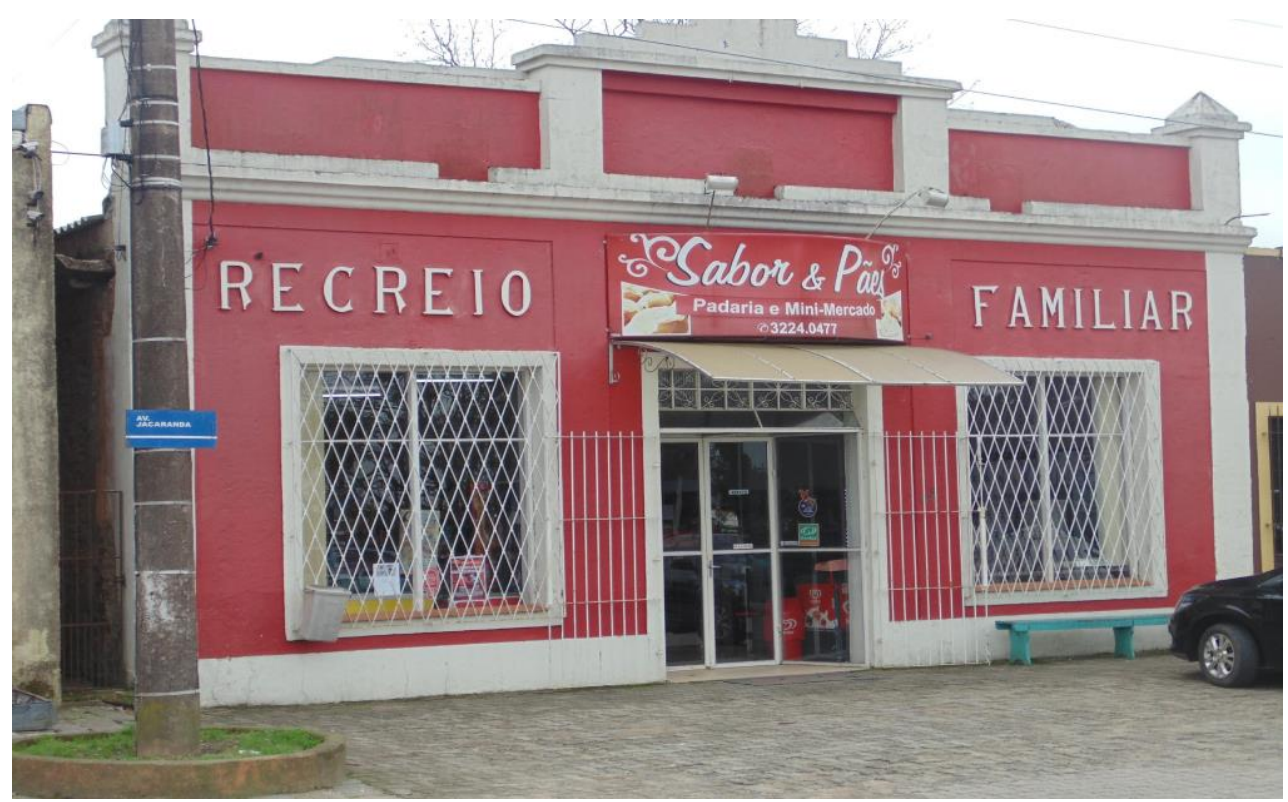

Fotografia 4: Recreio familiar atualmente

Fonte: Da autora, 2018.

\section{Conclusões}

Normalmente, partimos de decisões políticas e institucionais para declaração de um patrimônio, porém precisamos extrapolar essas questões pré-construídas no momento em que a população se apropriar e reconhecer sua identidade em determinada "coisa". Essa é a construção de um patrimônio partindo de um campo subjetivo e imaginário e não de algo concreto e objetivo. $\mathrm{O}$ artefato pode ser constituído e, assim, ganhar valor pela a imaginação de quem o enxerga, podendo ser visto de vários ângulos e feições, sendo capaz de ser modificado e adaptado conforme variadas interpretações.

Com a participação da maioria da população, com a contribuição de técnicos de gestão patrimonial e agentes locais que estão envolvidos no desenvolvimento da comunidade local, podemos chegar mais próximos de um patrimônio que extrapole as questões jurídicas, que destacam as monumentalidades, e realçar os valores subjetivos, aproximando o campo das sensibilidades. Os patrimônios, sendo eles localmente construídos ou não, devem dispor de utilidade social e participação. Os patrimônios locais deveriam ser reintroduzidos no uso das comunidades, pois assim ganhariam um ideal, especialmente presentes nas experiências da população.

\section{Referências}

COOPER, C; ARCHER, B. Os impactos positivos e negativos do turismo. In Theobald, W. F (org.). Turismo Global. São Paulo: Editora Senac, 2001. 
CORIOLANO, L. N. M. T; LIMA, L. C. (orgs.). Turismo Comunitário e Responsabilidade Sócio Ambiental. Fortaleza: EDUECE, 2003.

DE VARINE, H. As raízes do futuro: o patrimônio a serviço do desenvolvimento local. Trad. de Maria de Lourdes Parreiras Horta. Porto Alegre: Medianiz, 2012. 256 p.

DECLARAÇÃO DE QUÉBEC: Sobre a preservação do "Spiritu loci". Assumido em Québec, Canadá, em 4 de outubro de 2008. Disponível em: $<$ http://www.icomos.org/quebec2008/quebec declaration/pdf/GA16_Quebec Declarat on_Final_PT.pdf

DOHMANN, M. A experiência material: a cultura do objeto. Rio de Janeiro: Rio Books, 2013.

HALBWACHS, M. A Memória Coletiva. Rio de Janeiro: Vertice, 1990. . Los Marcos Sociales de la Memoria. Caracas, Anthropos Editorial, 1976.

IBGE. Censo Demográfico, 2018. Disponível em: https://cidades.ibge.gov.br/brasil/rs/morroredondo/panorama. Acesso em: 25 de jul, 2018.

LUCHIARI, M T. D. P. Urbanização turística: um novo nexo entre lugar e o mundo. In Lima, Luiz Cruz (org). Da cidade ao campo: a diversidade do saber-fazer turístico. Fortaleza. UECE, 1998, p. 15-29.

NORA. P. 1993. Entre a Memória e História: A problemática dos lugares. Trad: Yara Aun Khoury. In: Projeto História, São Paulo: dez.

PRATS, L. Concepto y gestión del patrimonio local. Cuadernos de Antropología Social No 21, pp. 17-35, 2005.

Prefeitura Municipal de Morro Redondo. Disponível em: http://www.pmmorroredondo.com.br/historia.html. Acesso em: 14 de dez, 2018. 